\title{
Who is the Right Patient for Trans-Catheter Mitral Edge-to-Edge Repair?
}

\author{
Ching Wei Lee ${ }^{1,2,3,4}$ and Shih Hsien Sung ${ }^{1,3 *}$ \\ ${ }^{1}$ Department of Medicine, Taipei Veterans General Hospital, Taiwan \\ ${ }^{2}$ Department of Medical Affairs and Planning, Taipei Veterans General Hospital, Taiwan \\ ${ }^{3}$ Cardiovascular Research Center, National Yang-Ming University, Taiwan \\ ${ }^{4}$ Institute of Health Policy and Management, National Taiwan University, Taiwan
}

Submission: May 25, 2018; Published: July 13, 2018

*Corresponding author: Shih Hsien Sung, Division of Cardiology, Department of Medicine, Taipei Veterans General Hospital, Taipei, Taiwan, Tel: (866)-2-28712121; Fax: (886)-2-28717431; Email: mr.sungsh@gmail.com

\begin{abstract}
Compare to surgical mitral valve intervention, trans-catheter mitral edge-to-edge repair show better procedural safety in patients with severe mitral regurgitation (MR). On the other hand, there is still a concern that more recurrent MR is observed in surgical eligible patients treated with Mitra Clip. As a result, trans-catheter mitral edge-to-edge repair is reserved for subjects with high or prohibitive surgical risk. In the real-world practice, majority of subjects with advanced age, severely depressed left ventricular systolic function, or in critical conditions are put in medical treatment alone rather than either surgical or trans-catheter mitral intervention. To improve the utilization of Mitra Clip in suitable patients, we will go through current evidence to identify the procedural safety and efficacy for trans-catheter mitral repair.
\end{abstract}

Keywords: Mitral regurgitation; Trans-catheter mitral valve repair

\section{Disease Burden of Mitral Regurgitation(MR)}

More than $10 \%$ of the subjects, aged $\geq 75$ years have moderate to severe mitral regurgitation (MR) [1]. MR is a debilitating, progressive and life-threatening disease, which occurs when the leaflets of the mitral valve do not close completely, causing blood to flow backwards into the left atrium of the heart and the lungs during the cardiac cycles. Patients with symptomatic severe MR, if left untreated, would experience progressive heart failure, and the 5 -year mortality rate could be as high as $50 \%$ [2]. The etiology of MR is classified as degenerative MR (pro-lapsing leaflets or rupture chordae) and functional MR (consequence of annulus dilatation or abnormal left ventricular function) [3]. The burden of MR is substantial along with the prolonging of life expectancy, the trend of deaths related with valvular heart disease upstroke significantly in the past three decades [4]. Of the 39 billion in annual heart failure costs in the US, approximately $60 \%$ is due to heart failure hospitalization, many of which are associated with MR [5].

Clinical Unmet Need in Treating Patients with Severe MR who Carries High Surgical Risk or Advanced Age

The current therapeutic option for clinical significant MR is open-heart surgery to repair or replace the mitral valve. However, it is mandatory to use cardiopulmonary bypass in open-heart surgery, which could be a challenge to patient with advanced age or poor left ventricular systolic function. In fact, patients who are deemed too high risk to undergo mitral valve surgery have no other treatment option except ineffective medical therapy alone. More than $85 \%$ of the octogenarians and patients with poor left ventricular systolic function $(\mathrm{LVEF}<30 \%)$ who are declined to receive open-heart surgery because of high or prohibitive surgical risk [6]. The expected number of underutilization in mitral valve surgery could be higher in Asians due to culture differences between east and west. There is a clinical unmet need in treating severe MR properly.

\section{Trans-catheter mitral valve repair with Mitra clip}

After the safety and efficacy been proven in the randomized controlled trial, the Endovascular Valve Edge-to-Edge Repair Study (EVEREST II) [7,8], Mitra Clip (Abbott Vascular, Menlo Park, CA, USA) received FDA approval on October 24, 2013 and is indicated for the percutaneous reduction of significant symptomatic MR in patients who have been determined to be prohibitive risk for mitral valve surgery by a heart team. Over the last 10 years, multiple clinical studies have been performed to establish a reasonable safety and long-term impact on improvement in quality of life for this procedure. On the other hand, there is still 
a concern that more recurrent MR is observed in patients treated with Mitra clip compared to surgical mitral valve intervention. As a result, trans-catheter mitral edge-to-edge repair is reserved for subjects with high or prohibitive surgical risk [9].

\section{Transcatheter mitral valve repair or open-heart surgery in elderly patients}

Murashita et al. [10] demonstrated acceptable procedure safety (7.3\% in-hospital mortality) and long-term survival $(81 \%$ at 5 years) in subjects older than 75 years who underwent surgical mitral valve repair. However, limited case number $(\mathrm{N}=55)$ and single center design are the main limitations of this research. The mean age of the elderly patients is 77 years old, which is also not representative to octogenarians [10]. By systemic review and meta-analysis, Andalib et al. [11] showed surgical treatment of MR in octogenarians is associated with high preoperative mortality (7-13\% post-operative mortality) and poor long-term survival (67\% and $29 \%$ survival rate at 1 and 5 years) with an uncertain benefit on quality of life. On the other hand, Buzzatti et al. [12] found 25 octogenarians who underwent Mitra Clip, despite being older, more symptomatic and affected by more co morbidities showed significantly reduced postoperative complications $(\mathrm{P}<0.05)$ as compared to surgical groups $(\mathrm{N}=35)$. From GRASP (Getting Reduction of Mitral Insufficiency by Percutaneous Clip Implantation) registry, Mitra Clip was shown to be safe and effective in most patients, with similar hospital length of stay, one-year clinical outcomes and re-hospitalization rates in either elderly or younger patients [13].

\section{Transcatheter mitral valve repair or open-heart surgery in patients with severely depressed LVEF}

For patients with severe degenerative MR and LVEF less than $30 \%$, optimal medical treatment is the frontline therapy suggested by the current guideline because of high risk for peri-operative mortality and morbidities. From the Euro SCORE II risk prediction model, subjects with $\mathrm{LVEF}<30 \%$ will carry $40 \%$ increased risk in open-heart surgery $[14,15]$. Left ventricular systolic dysfunction, a traditional risk predictor in surgical prediction model is not associated with worse outcome after trans-catheter mitral valve repair. Barth et al. [16] demonstrated fair procedural safety and even similar improvements in exercise capacity in both patients with advanced LV dysfunction ( $\mathrm{LVEF}<20 \%)$ or not [17].

\section{Transcatheter mitral valve repair or open-heart sur- gery in patients under critical conditions}

Emergent open-heart surgery to rescue patients under mechanical hemodynamic support is really challenging, especially when patients carry multiple co-morbidities. Several case reports have demonstrated Mitra Clip can be used to rescue patients under extracorporeal membrane oxygenation (ECMO) support [18] and even with acute myocardial infarction (AMI) and papillary muscle rupture $[19,20]$. Adamo et al. [21] showed critically ill patients with acute ischemic MR can benefit from Mitra Clip procedure acutely with favorable long-term follow-up results. In our center, we have treated 1 patient under ECMO support and 1 patient with acute papillary muscle rupture after AMI. Both patients recovery well and can discharge to home after emergent procedure. The value of trans-catheter intervention in critical illness is safe and effective procedure per se.

\section{Anatomic consideration for transcatheter mitral valve repair}

To date, the EVEREST criteria have been acknowledged as the basic of an anatomical selection process. In EVEREST study, the anatomical eligible for Mitra Clip procedure comprised that a primary regurgitation originating from central A2/P2 region, cooptation length greater than $2 \mathrm{~mm}$ and cooptation depth less than $11 \mathrm{~mm}$ in FMR, and flail gap less than $10 \mathrm{~mm}$ and width less than $15 \mathrm{~mm}$ in DMR [22]. However, there were only limited cases to fulfill the strict echocardiography criteria for Mitra Clip procedure. In fact, Attizzani et al. [23] have shown with reasonable expanded echocardiography features, the safety and efficacy are comparable to EVEREST eligible patients. However, patients with mitral cleft, rheumatic mitral stenos is, active endocarditic, or inadequate length of posterior mitral leaflet $(<7 \mathrm{~mm})$ are discouraged to receive Mitra Clip procedure.

\section{Conclusion}

Trans-catheter edge-to-edge mitral valve repairs are safe and effective in patients with severe MR who carry high or prohibitive surgical risk. Mitra Clip is an alternative or even the only solution to rescue severe MR patients with advanced age, poor left ventricular systolic function, or critical conditions under mechanical support.

\section{References}

1. Nkomo VT, Gardin JM, Skelton TN, Gottdiener JS (2006) Burden of valvular heart diseases: a population-based study. Lancet 368: 10051011.

2. Goel SS, Bajaj N, Aggarwal B, Gupta S, Poddar KL, et al. (2014) Prevalence and outcomes of unoperated patients with severe symptomatic mitral regurgitation and heart failure: comprehensive analysis to determine the potential role of mitra clip for this unmet need. Journal of the American College of Cardiology 63: 185-186.

3. Enriquez Sarano M, Akins CW, Vahanian A (2009) Mitral regurgitation. Lancet 373(9672): 1382-1394.

4. Coffey S, Cox B, Williams MJ (2014) Lack of progress in valvular heart disease in the pre-transcatheter aortic valve replacement era: increasing deaths and minimal change in mortality rate over the past three decades. Am Heart J 167(4): 562-567.

5. Braunschweig F, Cowie MR, Auricchio A (2011) What are the costs of heart failure? Europace Suppl 2: ii13-ii17.

6. Mirabel M, Iung B, Baron G, Messika Zeitoun D, Détaint D, et al. (2007) What are the characteristics of patients with severe, symptomatic, mitral regurgitation who are denied surgery? Eur Heart J 28(11): 1358-1365.

7. Feldman T, Foster E, Glower DD, Kar S, Rinaldi MJ, et al. (2011) Percutaneous repair or surgery for mitral regurgitation. N Engl J Med 364(15): 1395-1406. 
8. Feldman T, Kar S, Elmariah S, Smart SC, Trento A, et al. (2015) Randomized comparison of percutaneous repair and surgery for mitral regurgitation: 5-year results of EVEREST II. J Am Coll Cardiol 66(25): 2844-2854.

9. Nishimura RA, Otto CM, Bonow RO, Carabello BA, Erwin JP, et al. (2017) AHA/ACC focused update of the 2014 AHA/ACC guideline for the management of patients with valvular heart disease: A report of the American college of cardiology/American heart association task force on clinical practice guidelines. J Am Coll Cardiol 70: 252-289.

10. Murashita T, Okada Y, Kanemitsu H, Fukunaga N, Konishi Y, et al. (2014) Feasibility and efficacy of mitral valve repair for degenerative mitral regurgitation in the elderly. Ann Thorac Cardiovasc Surg 20(6): 10011007.

11. Andalib A, Mamane S, Schiller I, Zakem A, Mylotte D, et al. (2014) A systematic review and meta-analysis of surgical outcomes following mitral valve surgery in octogenarians: implications for transcatheter mitral valve interventions. Euro Intervention 9(10): 12251234.

12. Buzzatti N, Maisano F, Latib A, Taramasso M, Denti P, et al. (2015) Comparison of outcomes of percutaneous mitra Clip versus surgical repair or replacement for degenerative mitral regurgitation in octogenarians. Am J Cardiol 115(4): 487-492.

13. Scandura S, Capranzano P, Caggegi A, Grasso C, Ronsivalle G, et al. (2016) Percutaneous mitral valve repair with the mitra Clip system in the elderly: One-year outcomes from the GRASP registry. Int J Cardiol 224: 440-446.

14. Baumgartner H, Falk V, Bax JJ, De Bonis M, Hamm C, et al. (2017) ESC/ EACTS Guidelines for the management of valvular heart disease. Eur Heart J 38(26): 2739-2791.

15. Nashef SA, Roques F, Sharples LD, Nilsson J, Smith C, et al. (2012) Euro SCORE II. Eur J Cardiothorac Surg 41(4): 734-744.
16. Kaneko H, Neuss M, Schau T, Weissenborn J, Butter C (2016) Impact of left ventricular systolic dysfunction on the outcomes of percutaneous edge-to-edge mitral valve repair using mitraClip. Heart Vessels 31(12): 1988-1996.

17. Barth S, Hautmann MB, Kerber S, Gietzen F, Reents W, et al. (2017) Left ventricular ejection fraction of $<20 \%$ : Too bad for MitraClip((c))? Catheter Cardiovasc Intervations 90(6): 1038-1045.

18. Staudacher DL, Bode C, Wengenmayer T (2015) Severe mitral regurgitation requiring ECMO therapy treated by interventional valve reconstruction using the mitra Clip. Catheter Cardiovasc Interv 85(1): 170-175.

19. Tarsia G, Smaldone C, Costantino MF (2016) Effective percutaneous "edge-to-edge" mitral valve repair with mitraclip in a patient with acute post-MI regurgitation not related to papillary muscle rupture. Catheter Cardiovasc Interv 88(7): 1177-1180.

20. Bahlmann E, Frerker C, Kreidel F, Thielsen T, Ghanem A, et al. (2015) MitraClip implantation after acute ischemic papillary muscle rupture in a patient with prolonged cardiogenic shock. Ann Thorac Surg 99(2): e41-e42.

21. Adamo M, Curello S, Chiari E, Fiorina C, Chizzola G, et al. (2017) Percutaneous edge-to-edge mitral valve repair for the treatment of acute mitral regurgitation complicating myocardial infarction: A single centre experience. Int J Cardiol 234: 53-57.

22. Feldman T, Cilingiroglu M (2011) Percutaneous leaflet repair and annuloplasty for mitral regurgitation. Journal of the American College of Cardiology 57(5): 529-537.

23. Attizzani GF, Ohno Y, Capodanno D, Cannata S, Dipasqua F, et al. (2015) Extended use of percutaneous edge-to-edge mitral valve repair beyond EVEREST (Endovascular Valve Edge-to-Edge Repair) criteria: 30-day and 12-month clinical and echocardiographic outcomes from the GRASP (Getting Reduction of Mitral Insufficiency by Percutaneous Clip Implantation) registry. JACC Cardiovascular Interventions 8(1): 74-82.

Your next submission with Juniper Publishers
will reach you the below assets
- Quality Editorial service
- Swift Peer Review
- Reprints availability
- E-prints Service
- Manuscript Podcast for convenient understanding
- Global attainment for your research
- Manuscript accessibility in different formats
( Pdf, E-pub, Full Text, Audio)
- Unceasing customer service
Track the below URL for one-step submission
https://juniperpublishers.com/online-submission.php

